\title{
Can anti-smoking television advertising affect smoking behaviour? Controlled trial of the Health Education Authority for England's anti-smoking TV campaign
}

\author{
Dominic McVey, John Stapleton
}

\begin{abstract}
Objectives-To evaluate the effectiveness of the Health Education Authority for England's anti-smoking television advertising campaign in motivating smokers to give up and preventing relapse in those who had already given up.

Design-A prospective, controlled trial was conducted in four TV regions in central and northern England. One region received no intervention (controls), two regions received $\mathrm{TV}$ anti-smoking advertising (TV media), and one region received TV anti-smoking advertising plus locally organised anti-tobacco campaigning (TV media + LTCN). The TV advertisements were screened in two phases over 18 months; during the first phase the intensity of the advertising was varied between TV regions. 5468 men and women (2997 smokers, 2471 ex-smokers) were selected by two stage random sampling and interviewed before the intervention, of whom 3610 were reinterviewed six months later, after the first phase of the campaign. Only those interviewed at six months were followed to the main end point at 18 months when 2381 subjects were re-interviewed.

Main outcome measures-Self reports of cigarette smoking at the $\mathbf{1 8}$ month follow up were compared between the three levels of intervention. Odds ratios for intervention effects were adjusted for preintervention predictors of outcome and pooled for smokers and ex-smokers using meta-analytic methods.
\end{abstract}

Results-After 18 months, $9.8 \%$ of successfully re-interviewed smokers had stopped and $4.3 \%$ of ex-smokers had relapsed. The pooled adjusted odds ratio for not smoking in the TV media only condition compared to controls was $1.53(95 \%$ confidence intervals (CI) 1.02 to 2.29 , $p=0.04)$, and for TV media + LTCN versus controls, 1.67 (95\% CI 1.0 to 2.8 , $\mathbf{p}=\mathbf{0 . 0 5}$ ). There was no evidence of an extra effect of the local tobacco control network when combined with TV media (odds ratio $1.15,95 \%$ CI 0.74 to 1.78 , $p=0.55)$. The was also no evidence of any intervention effects after the first phase of the TV media campaign, including no effect of varying the intensity of the adver- tising during this initial phase. Applying these results to a typical population where $28 \%$ smoke and $28 \%$ are ex-smokers, and where there would be an equal number of quitters and relapsers over an 18 month period without the campaign, suggests that the campaign would reduce smoking prevalence by about $1.2 \%$.

Conclusions-The Health Education Authority for England's anti-smoking TV campaign was effective in reducing smoking prevalence through encouraging smokers to stop and helping prevent relapse in those who had already stopped. The lack of an effect after the first phase of the campaign indicates that if advertising at this intensity is to have an impact, a prolonged campaign is necessary. These results support the UK governments' recent decision to fund similar campaigns, and suggests that anti-smoking TV advertising should be undertaken routinely as an essential component of any population smoking reduction strategy. Reducing smoking prevalence would make a substantial contribution to achieving the UK government's target of preventing 300000 cancer and heart disease deaths over the next 10 years.

(Tobacco Control 2000;9:273-282)

Keywords: anti-smoking TV campaign; England; smoking cessation

Cigarette smoking remains the largest single cause of premature death in developed countries, accounting for almost $20 \%$ of all mortality. Those who smoke throughout their lives are as likely to die from smoking as they are from all other causes. ${ }^{1}$ In the UK, smoking is responsible for almost one million cancer and heart disease deaths every 10 years and is a major contributor to the health divide between rich and poor. Although the dangers of smoking have been known for many years, governments have been slow to react and counter the problem with the type of resources and legislation frequently brought to bear on other, far less devastating, public health problems. The old maxim that prevention is better than cure seems not to have been heeded in relation to diseases caused by smoking.

The recent White Paper, "Smoking kills", represented a major change in UK government attitude. ${ }^{2}$ For the first time government fully recognised the nature of the problem and that 


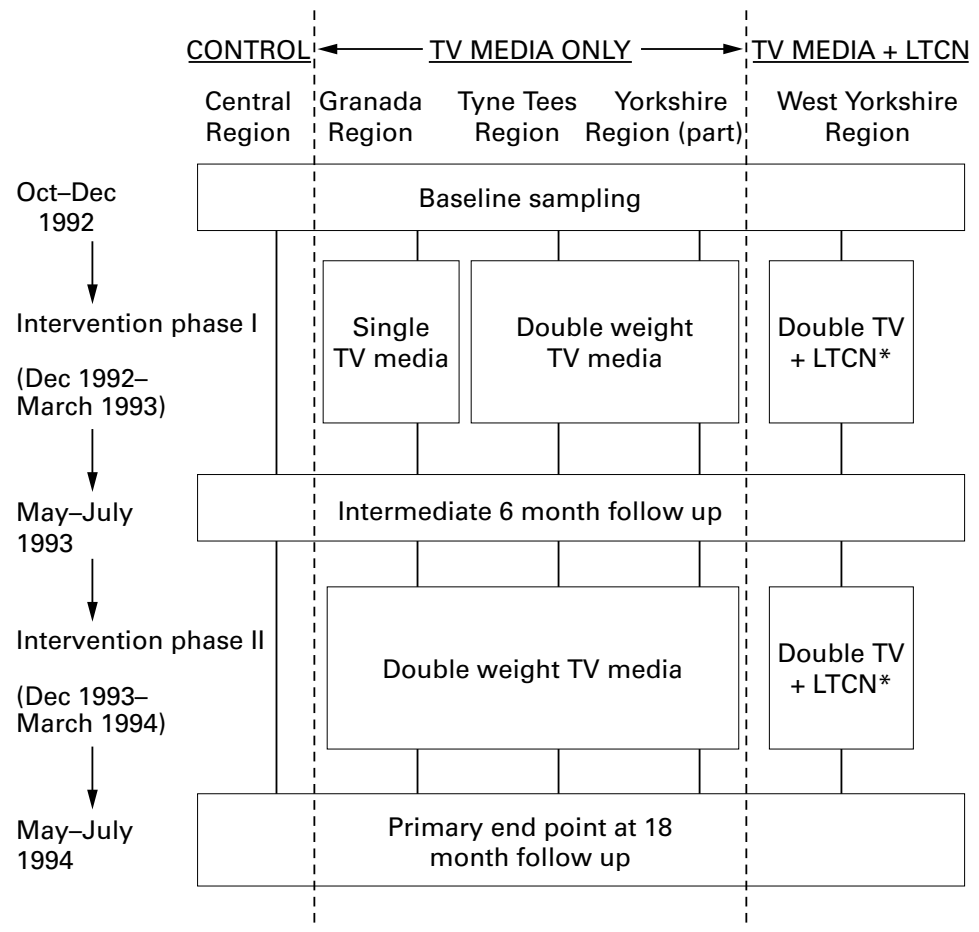

* LTCN ran continuously from October 1992

Figure 1 Study design and timetable.

substantial resources would need to be deployed to reduce the prevalence of smoking and hence reduce the scale of the tobacco epidemic. The White Paper pledged about $£ 110$ million over three years to be divided roughly equally between two complementary interventions: an anti-smoking publicity campaign to "shift attitudes and change behaviour": and new smoking cessation treatment services within the National Health Service. This dual approach can be viewed as providing the motivational stimulus needed to encourage more smokers to try to stop, and also the professional help to the many who are unable to break their tobacco dependence unaided.

Evidence for the effectiveness and cost effectiveness of clinical interventions for tobacco dependence has accumulated rapidly in recent years through hundreds of studies of nicotine replacement and other pharmaceutical products in a range of settings. ${ }^{34}$ By comparison, there have been far fewer studies into the effect of anti-smoking publicity campaigns. There is currently no Cochrane review in the field and the most recent meta-analysis dates back to $1987 .^{5}$ The last published UK study of anti-smoking television advertisements also dates back to $1987 .{ }^{6}$ Probably the main reason why mass media interventions have been studied far less than clinical interventions is that evaluations of mass media programmes are inherently more difficult and costly to conduct, because of the large samples required to detect the relatively small effects expected at the individual level. Also, there is only very limited potential for mass media interventions to receive the kind of commercial support that clinical interventions have received from the pharmaceutical industry. However, since mass media campaigns can reach whole populations, where even small individual effects can have a major overall impact, it appears that this approach has been erroneously neglected by health promotion commissioners.

If there has been a particular sparsity of UK studies into mass media interventions in the last few years, then the position has been somewhat healthier in other countries, most notably in the USA and Australia. Here there have been a number of statewide anti-smoking campaigns and several of these have been the subject of evaluative studies. Interestingly, all these reports have been evaluations of actual interventions, rather than a priori experimental examinations of which intervention options might be the most effective.

Following the lead shown by California ${ }^{7-9}$ in the late 1980s, similar comprehensive statewide programmes have been introduced in Massachusetts $^{1011}$ and Oregon. ${ }^{12}{ }^{13}$ These programmes shared three common themes: (1) tax increases on tobacco products simultaneous with mass media education and publicity campaigns; (2) multi-component education and publicity mass media campaigns; (3) extensive use of anti-smoking TV advertising. Using mainly cross sectional survey data sampled before, during, and after the programmes, all states reported a reduction in per capita cigarette consumption and smoking prevalence relative to other US states. Although the effects of the tax increases and the education and publicity campaigns were confounded in these programmes, an analysis of the California campaign suggests that both elements were effective. ${ }^{9}$ Additional support for the independent effectiveness of the education and publicity campaigns comes from Massachusetts where the tax increase was quickly offset by manufacturers' price reductions. In none of these programmes was it possible to assess the independent effect of the TV advertising component. However, support for the effectiveness of anti-smoking TV advertising had previously come from the "Quit for Life" campaign in Sydney and Melbourne, Australia. Starting in Sydney in 1983 this campaign used TV advertisements as the predominant element in a multi-component publicity and treatment programme. ${ }^{14}{ }^{15}$ In a cohort study over the first year, the prevalence of smoking in Sydney was seen to decline relative to that in Melbourne, where the campaign was not introduced until 1984. In a later study, cross sectional surveys in both cities showed a decline in prevalence following the introduction of the campaigns. In men, the decline continued throughout the campaign period until $1986 .{ }^{16}$ After a break of more than 10 years a similar campaign was introduced nationwide in Australia in 1997. Again the major component was TV advertisements, this time with a strong fear arousal theme. Cross sectional surveys before and after the six month campaign showed a $1.5 \%$ reduction in smoking prevalence and there were also positive changes on a range of ancillary measures. ${ }^{17}$

To evaluate the specific effect of anti-smoking TV advertising the Health 


\section{Box 1: TV media campaign}

A series of qualitative pilot research studies using focus groups and in depth interviews with smokers and ex-smokers identified the following campaign objectives:

- Motivate smokers to attempt to give up by providing information on the health risks of smoking.

- Provide supporting advice for smokers' efforts to quit and stay quit.

- Display an understanding of the difficulties of stopping.

- Build smokers' confidence in their ability to stop.

It was clear from the qualitative research in this population that purely "health shock" publicity featuring, for example, cancerous lungs and blocked arteries had become passé. Also, there seemed to be few new messages to convey about the risks of smoking, but that information on the short term benefits of giving up and the effects of parental smoking on children could be highlighted. Furthermore, it was important that the overall tone of campaign should be "anti-smoking" not "anti-smoker". The research revealed that using celebrity endorsement would offer most potential to convey these messages in a supportive way. The actor and comedian John Cleese, an ex-smoker, agreed to take part in the campaign. During focus groups and in-depth interviews with smokers and ex-smokers, over 20 pilot advertisements were tested featuring John Cleese talking directly to the viewer in a series of sketches. They featured him trying to give up smoking, trying not to relapse, and imparting information about the effects of smoking on the smoker and those around them, particularly the effects on children.

The style of the advertisements was to use morbid or "black" humour and somewhat macabre or bizarre scenarios to engage the viewer and underline the messages (figs 2 and 3). One advertisement started with Cleese as a dead man on a slab in an empty, lonely, morgue. As the camera pans in, he sits up to "talk seriously about giving up smoking". He then talks about the dangers of smoking, gives encouragement in the form of figures on how many others have succeeded in stopping etc, before finishing with "give up - it's better than being one of these". He lies down again and pulls the cover over himself. Another scene has him sitting at a table, facing the camera, pouring ashes from an urn onto the table, "let me show you how much ash a 20 -a-day smoker makes?". The initial impression is that he is saying smoking is messy, unpleasant, and that cigarettes produce just a lot ash. He finishes with the words, "of course, they're not all cremated-some are buried". Many of the scenes featured him "toughing out" withdrawal symptoms after he had quit and giving tips on how to get through the month when they are more severe. Another scenario has him in a domestic situation as an ex-smoker confronted by a smoker. The smoker is portrayed as a robot, who repeatedly and mechanically tries to get him to take a cigarette.

The end of every advertisement featured a "Quitline" number to call for further information and advice about trying to give up smoking. Quitline is funded by the HEA, and callers could leave their name and number and receive a free booklet and/or talk to a counsellor for advice.

During the course of the campaign the help line service received approximately 20000 calls from within the intervention regions.

Education Authority for England (HEA) conducted a controlled study in central and northern England. The advertisements were designed to raise awareness and to motivate and encourage smokers to stop, and ex-smokers to stay stopped. Secondary aims were to evaluate the additional effect of local community anti-smoking activity and also of varying the intensity of the TV advertising.

\section{Methods}

INTERVENTIONS

The study was conducted in four central and northern English independent TV regions
(Central, Granada, Tyne Tees, and Yorkshire) between October 1992 and May 1994 (fig 1). No anti-smoking advertisements were shown by Central TV, which acted as the control region. In Granada, Tyne Tees, and part of Yorkshire the intervention comprised only the TV advertising campaign (TV media). In West Yorkshire the intervention comprised both the TV campaign and a local tobacco control network (TV media plus LTCN). Following the successful completion of the study phases of the campaign reported here the TV advertisements were shown nationally in all TV regions in England.

The allocation of intervention conditions to regions was not by random assignment, but on the basis of practical and ethical considerations. Although the evaluation phases were designed primarily as a rigorous assessment of the effectiveness of the interventions, the fact could not be ignored that the interventions might have a substantial positive effect on smoking behaviour in the regions chosen. We therefore felt that, given the considerable health budget involved, there was an imperative that the study media intervention should take place in regions of England with the highest smoking prevalence, where there was the greatest need to reduce smoking. Hence, Granada, Tyne Tees and Yorkshire were allocated to media intervention. Central was chosen as the control region since it was geographically and also demographically close to the preselected media intervention regions. Of all the areas available within the media intervention regions for a local tobacco control network, West Yorkshire was chosen because their pre-existing anti-smoking activities seemed to have the greatest potential to develop a vigorous local activity network in a relatively short space of time. The lack of randomisation of regions to interventions was not considered to be a significant handicap for the study, since: (1) the number of regions was small and randomisation could not possibly equalise differences between regions; and (2) we planned to adjust the comparisons of outcome between the interventions for any potentially confounding background characteristics (see below).

The TV advertisements were screened in two phases over 18 months. The same advertisements were shown in all intervention regions but the intensity of advertising was varied during the first phase of the campaign. Single weight advertising was screened in Granada and double weight in Tyne Tees and Yorkshire. For the second phase of the TV campaign double weight advertising was screened in all three TV test regions.

\section{TV MEDIA CAMPAIGN}

The TV advertisements were aimed at current adults smokers and those who had already given up. During the first phase (December 1992 to March 1993) 10 different advertisements ranging in length from 30-40 seconds were shown. All featured the actor and comedian John Cleese at various stages of quitting, imparting risk messages, encouraging 


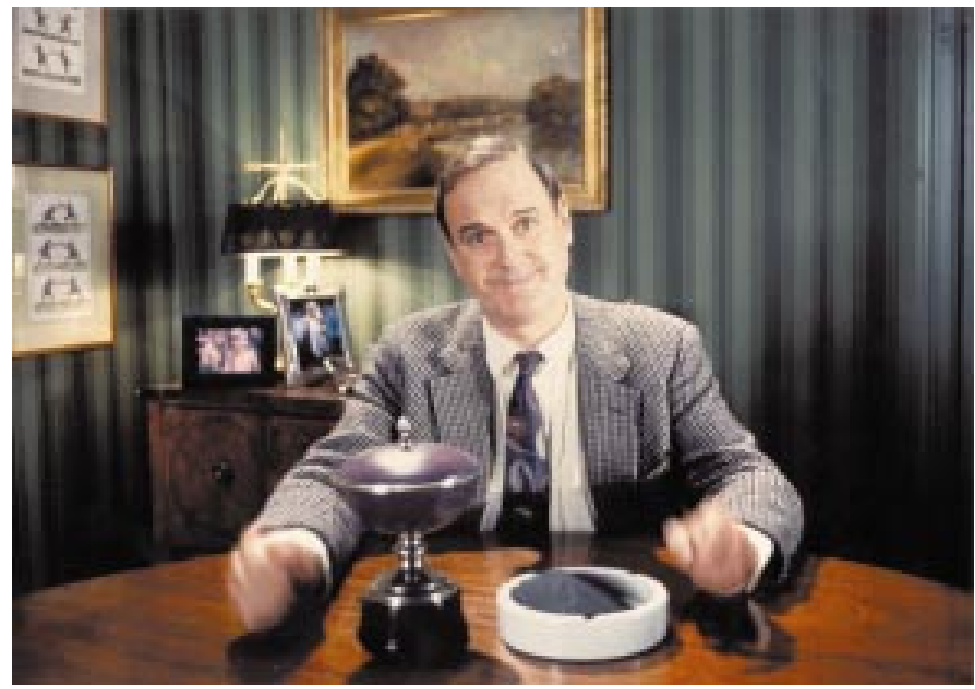

Figure 2 "Let me show you how much ash a 20 a day smokers makes - of course, not all are cremated".

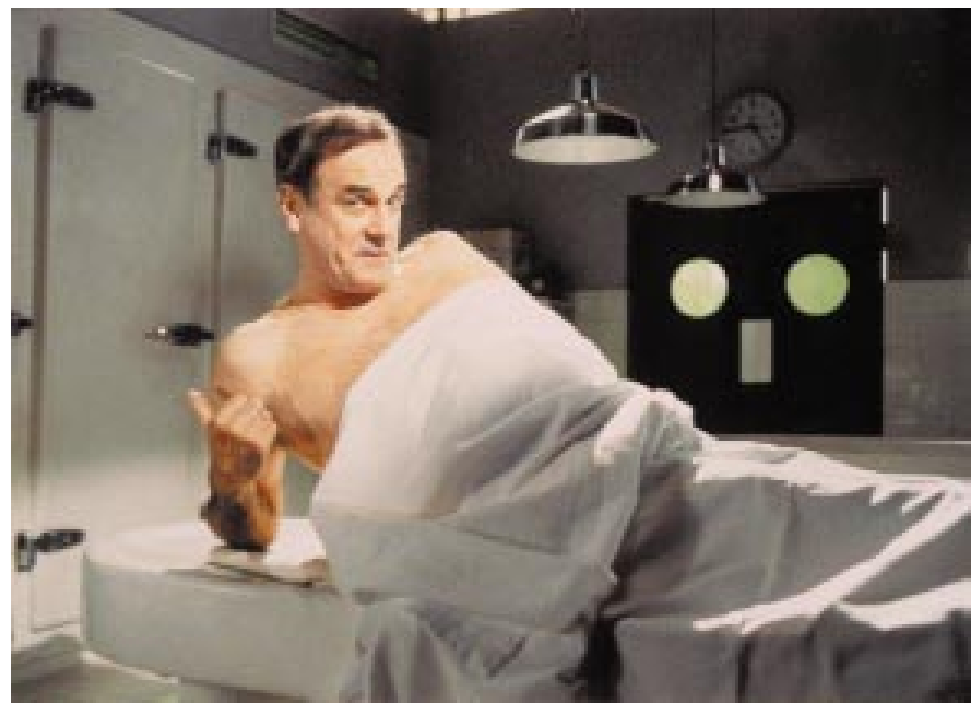

Figure 3 "Give up_it's better than being one of these."

attempts at quitting, and providing supportive tips on how to prevent relapse. Following a qualitative market research evaluation during May to July 1993, five of the 10 advertisements were replaced with four new ones to keep the campaign fresh, and these were shown during the second phase from December 1993 to March 1994. The style and content of the advertisements was chosen following pilot research. Most advertisements used morbid humour and bizarre or macabre scenarios related to smoking. They aimed first to engage the viewers' curiosity, then to highlight the dangers of smoking, show the ridiculousness of the smoking habit and, finally, to "point up" the quitting messages (see box 1 for more details). It was felt that John Cleese was ideally suited to this style of campaign, having previously featured in a number of very popular TV series (Monty Python, Fawlty Towers) and films (Fish Called Wanda, Clockwise) which often included bizarre or macabre humour. Anti-smoking TV advertisements using humorous elements have previously been used with success in Australia ${ }^{18}$.
Air time was purchased during a range of programmes to ensure maximum exposure. For the first phase, only half as much air time was purchased in the Granada region (single weight) as in Tyne Tees and Yorkshire (double weight). From a media evaluation survey it was estimated that over the course of the campaign each viewer would have seen at least 20 screenings in the double weight regions (approximately 10 per phase) and about three quarters of this number in the single weight region (approximately five in the first phase and 10 in the second phase).

LOCAL ANTI-SMOKING CAMPAIGN

In West Yorkshire the HEA funded a local tobacco control network of health promotion workers in addition to the TV advertisements. Their goal was to reduce smoking in their communities by initiating and supporting a wide range of anti-smoking activities (box 2).

SUBJECTS AND SAMPLING

In October 1992, before the start of the campaign, a baseline sample of the population in each region was interviewed to record demographics, smoking history, and attitudes to smoking. The smoking questions formed only part of the interview, which also covered other health related behaviours and attitudes. The interviews were conducted in the homes of those sampled using a structured questionnaire and lasted about 30 minutes. Attempts were made to re-interview the same respondents six and 18 months later, after the first and second phases of the campaign. On both occasions a similar structured questionnaire was completed. A consortium of market research organisations conducted the sampling and interviewing. Boundary areas, where TV signals from adjacent regions overlap, were not sampled.

A two stage cluster sampling design was employed to select the initial sample. Within each TV region a random sample of enumeration districts ${ }^{19}$ were selected (1 in 40) and within each district a random sample of households were selected ( 1 in 20) using computer generated lists. Interviewers then visited the selected households and one resident member was selected for the sample using a pseudo-random Kish-grid method. ${ }^{20}$ Only adults, aged 16 or older, were sampled. Interviewers and respondents were unaware of the forthcoming TV campaign or of the intention to conduct follow up interviews. The decision not to tell respondents that they were taking part in a study risked higher non-contact and refusal rates at follow up than might be expected under a formal clinical trial protocol, but minimised the likelihood of high rates of deception about smoking status and follow up attrition related to the intensity of the intervention. The follow up interviews were conducted by a different group of field workers who were unaware of the pre-campaign responses or the relationship between the interviews and the interventions. They were instructed to make five attempts to re-interview the original respondent, failing 


\section{Box 2: The local tobacco control network}

The local tobacco control network was established with the help of HEA funding in West Yorkshire, an area that includes five large metropolitan areas with a total population of two million. Under the title "West Yorkshire Smoking \& Health" (WYSH), the network included representatives from the health sector, local authorities, and voluntary agencies. A health promotion specialist from a local health authority was seconded as a half time coordinator for the network. Support from the HEA consisted of assistance from the HEA press office and funding to initiate local activity and media training. The network provided an opportunity to initiate or strengthen collaboration between agencies and health promotion workers by pooling their resources to contribute in a concerted fashion to the campaign. Over 20 organisations were actively involved in WYSH during the intervention period and the network continues to exist six years after its formation. At the initial meeting of WYSH it was agreed that its mission was to create widespread support for a non-smoking society and to encourage and help smokers give up, through the following broad objectives:

- Generate unpaid publicity for tobacco control

- Extend smoke-free areas

- Promote the development of local smoking policies

- Stimulate local smoking cessation activities

- Monitor the benefits and pitfalls of healthy alliances on smoking prevention

Specific activities included:

- Media and cessation skills training for local health promotion workers

- Launch of the Roy Castle Good Air Awards

- Publication of the Guide to smoke-free eating and drinking

- Lobbying local politicians, restaurants, industry, and opinion formers

- Support the TV campaign by linking it with local messages

- Development of written materials

- Generation of publicity in the local press and on local TV and radio news

During the two year intervention period, the network produced a wide range of local activities, which generated substantial unpaid publicity, encouraged smoke-free areas in public places, and stimulated cessation activities in local communities. A comparative analysis of the local press coverage of smoking issues in the regions revealed that West Yorkshire generated significantly more news stories and unpaid publicity as a consequence of the activities of the local network than the other test regions and the control region.

which the follow up was abandoned. Respondents who could not be re-interviewed or who refused at six months were considered unlikely to respond subsequently, and no attempt was made to interview them at the primary end point at 18 months.

Only smokers and ex-smokers were included in this study. The questions used to define smokers and ex-smokers were similar to those used for many years by the UK General Household Survey. ${ }^{21}$ Current smokers were those who answered "yes" to the question, "do you smoke cigarettes at all nowadays?" and who also reported the number of cigarettes they smoked daily. Ex-smokers were those who did not report current smoking but who answered "yes" to the question, "have you ever smoked a cigarette, pipe or cigar?" and who also reported the number of cigarettes they had previously smoked. At follow up, smokers who reported not currently smoking were considered as having stopped and ex-smokers who reported current smoking were considered as having relapsed.

SAMPLE SIZE

The calculation of necessary sample size was initially based on anticipated differences in smoking cessation between the three intervention conditions after 18 months, when both phases of the campaign would have completed. Since the study would be measuring largely short term cessation, potentially subject to high relapse rates, an observed rate of $7 \%$ was expected in the control condition, based on previous UK cessation rates of about $2.5 \%$ lifetime quitters per annum. ${ }^{22} 23$ It was hoped that the TV advertising campaign alone might increase this by $50 \%$ to $10.5 \%$ and that TV media plus LTCN might double it, to $14 \%$. With $\alpha$ set at $0.05,4000$ successfully followed smokers would be required to detect the effect of TV advertising alone ( 0.9 power) and the additional effect of the LTCN (0.8 power). The sample was allocated approximately in the ratio 1:2:1 for Control, TV media, and TV media plus LTCN, respectively, to achieve these levels of power. Anticipating a $30 \%$ rate of non-response at follow up, 5800 smokers would be required at baseline. However, if the effects of the interventions on preventing relapse in ex-smokers were similar to those on cessation in smokers, such that the smoker and ex-smoker cohorts could be pooled using meta-analytic methods, then power would be significantly increased.

Because of logistical problems, the market research agencies were unable to sample as many respondents as planned before the launch of the campaign. Additionally, the attrition rate over the two follow ups was higher than expected. However, the effects of the intervention were sufficiently similar in smokers and ex-smokers to allow the two cohorts to be combined, giving a baseline sample of 5468 and partly redressing the loss of planned statistical power.

DATA ANALYSIS AND STATISTICAL METHODS Because the pre-intervention rates of smoking prevalence differed between the TV regions we did not attempt to evaluate directly the impact of the intervention on prevalence. Instead, we compared the interventions using the odds ratios of not smoking, calculated for smokers and ex-smokers and free from the actual numbers of smokers, ex-smokers, and never smokers in each population or the numbers sampled. Using varying assumptions, these effect measures could then be applied to any given population to estimate the impact on prevalence.

The principal outcome was smoking/not smoking after 18 months, when the full impact of the campaign would be most evident. The odds of smoking/not smoking were compared across the three intervention conditions in those followed, using odds ratios and $95 \%$ confidence intervals (CIs). The main comparisons were TV media versus control, and TV media plus LTCN versus TV media. Since randomisation was not possible in this setting, interventions 
Table 1 Details of sample and follow up

\begin{tabular}{|c|c|c|c|c|c|c|c|c|}
\hline & \multicolumn{2}{|l|}{ Control } & \multicolumn{2}{|c|}{$T V$ media only } & \multicolumn{2}{|c|}{$T V$ media $+L T C N$} & \multicolumn{2}{|l|}{ Total } \\
\hline & Smokers & Ex-smokers & Smokers & Ex-smokers & Smokers & Ex-smokers & Smokers & Ex-smokers \\
\hline Sampled at baseline & 719 & 775 & 1744 & 1256 & 534 & 440 & 2997 & 2471 \\
\hline \multicolumn{9}{|l|}{ Not eligible: } \\
\hline Moved/died & 38 & 19 & 110 & 38 & 42 & 9 & 190 & 66 \\
\hline Away/ill & 13 & 13 & 29 & 33 & 11 & 7 & 53 & 53 \\
\hline Inadequate details given & 27 & 28 & 139 & 55 & 17 & 19 & 183 & 102 \\
\hline Followed at 6 months ${ }^{\star}$ & $475(74 \%)$ & $571(80 \%)$ & $1064(73 \%)$ & $854(76 \%)$ & $334(72 \%)$ & $312(77 \%)$ & $1873(73 \%)$ & $1737(77 \%)$ \\
\hline \multicolumn{9}{|l|}{ Not followed: } \\
\hline Refused & 69 & 61 & 118 & 90 & 48 & 40 & 235 & 191 \\
\hline Not available after 5 calls & 36 & 29 & 105 & 60 & 32 & 18 & 173 & 107 \\
\hline Wrong respondent followed & 30 & 18 & 43 & 26 & 17 & 12 & 90 & 56 \\
\hline Reason not recorded & 31 & 36 & 136 & 100 & 33 & 23 & 200 & 159 \\
\hline Eligible for 18 month follow up & 438 & 526 & 960 & 794 & 290 & 288 & 1688 & 1608 \\
\hline \multicolumn{9}{|l|}{ Not eligible: } \\
\hline Moved/died & 28 & 30 & 81 & 36 & 37 & 18 & 146 & 84 \\
\hline Away/ill & 9 & 15 & 23 & 24 & 7 & 6 & 39 & 45 \\
\hline Followed at 18 months ${ }^{\star}$ & $288(66 \%)$ & $402(76 \%)$ & $673(70 \%)$ & $598(75 \%)$ & $198(68 \%)$ & $222(77 \%)$ & $1159(69 \%)$ & $1222(76 \%)$ \\
\hline \multicolumn{9}{|l|}{ Not followed: } \\
\hline Refused: & 60 & 40 & 88 & 55 & 27 & 15 & 175 & 110 \\
\hline Not available after 5 calls & 31 & 22 & 74 & 44 & 24 & 27 & 129 & 93 \\
\hline Wrong respondent followed & 1 & 3 & 3 & 4 & 2 & 1 & 6 & 8 \\
\hline Reason not recorded & 58 & 59 & 122 & 93 & 39 & 23 & 219 & 175 \\
\hline
\end{tabular}

${ }^{\star}$ Of those eligible for follow up.

and TV regions were necessarily confounded. Consequently, without adequate adjustment, any differences between the regions in the populations' propensity to change smoking behaviour would appear as intervention effects. Therefore, to compare the interventions on a like-for-like basis the odds ratios estimating intervention effects were adjusted for all pre-intervention predictors of change in smoking status. Also, it was not considered feasible to assign an outcome to those not followed, using intent-to-treat methodology. While such methods have good validity in high contact clinical treatment trials, where drop outs have invariably continued smoking, ${ }^{24}$ in this low intensity setting where subjects were unaware of the objectives or the interventions, no such assumption could be soundly applied. In our study, there were no grounds to suppose that the degree of change in smoking behaviour of drop outs would be different from that observed in those followed. However, as mentioned previously, we compared the samples followed on a like-for-like basis, by adjusting the odds ratios for all characteristics related to changing smoking behaviour. Background characteristics predictive of change for smokers and ex-smokers were first identified using multiple logistic regression models. Higher order and interaction terms were also considered. Type of occupation (manual/non-manual) was not recorded at baseline, and six month data were substituted. Dummy indicator variables were used to allow for missing data.

The smoker and ex-smoker cohorts were viewed as two separate studies, comparing identical interventions and using the same outcome measure-that is, smoking/not smoking. The adjusted odds ratios for smokers and ex-smokers were pooled to estimate a common intervention effect using the fixed effect metaanalysis method favoured by the Cochrane Review Centre. ${ }^{325}$ Approximately equal weight was given to smokers and ex-smokers in the pooled analysis owing to the similarity of the sample sizes in the two cohorts. In preliminary analyses, hierarchical random effect logistic models were fitted to test the effect of enumeration district within TV region and TV region within intervention condition. These had negligible, non-significant, effects on all comparisons and only the simpler models including intervention conditions and preintervention prognostic characteristics were used in the main analyses.

\section{Results}

SAMPLES AND FOLLOW UP

A total of 2997 smokers and 2471 ex-smokers were interviewed before the intervention (table 1). Twenty per cent of smokers and $14 \%$ of ex-smokers were ineligible for follow up at 18 months, because of having moved, died or not having provided sufficient information at baseline to be unambiguously identified again. Of those eligible, $73 \%$ of smokers and $77 \%$ of ex-smokers were successfully followed at six months. Only for those responding to the six month follow up was an 18 month follow up attempted. Of those eligible, $69 \%$ of smokers and $76 \%$ of ex-smokers were successfully re-interviewed at 18 months. The rate of successful follow up was similar between the three intervention conditions for both smokers and ex-smokers, but in all conditions ex-smokers were more frequently followed than smokers. A higher proportion of female than male smokers, and recent rather than longer-term ex-smokers, were followed (table 2). Otherwise, the demographic and baseline smoking characteristics of those followed and those not followed were similar. Any such differences were, however, adjusted for in the analysis of outcome (see below).

\section{IDENTIFYING CHARACTERISTICS PREDICTIVE OF} CHANGE

Since individual randomisation to interventions was not possible in this study, the 
Table 2 Demographics and smoking characteristics of sample

\begin{tabular}{|c|c|c|c|c|c|c|c|c|}
\hline & \multicolumn{2}{|l|}{ Control } & \multicolumn{2}{|c|}{ TV media only } & \multicolumn{2}{|c|}{$T V$ media $+L T C N$} & \multicolumn{2}{|l|}{ Total } \\
\hline & Smokers & Ex-smokers & Smokers & Ex-smokers & Smokers & Ex-smokers & Smokers & Ex-smokers \\
\hline \multicolumn{9}{|l|}{$\%(\mathrm{n})$ female } \\
\hline Followed at 18 months & $64.2(185)$ & $49.0(197)$ & $63.6(428)$ & $54.7(327)$ & $59.6(118)$ & $50.9(113)$ & $63.1(731)$ & $52.1(637)$ \\
\hline Not followed & $53.4(230)$ & $51.2(191)$ & $56.5(605)$ & $51.5(339)$ & $54.8(184)$ & $47.7(104)$ & $55.5(1019)$ & $50.8(634)$ \\
\hline \multicolumn{9}{|l|}{ Mean (SD) age } \\
\hline Followed at 18 months & $45.5(16.3)$ & $56.1(16.8)$ & $46.4(17.0)$ & $56.0(16.8)$ & $46.0(16.3)$ & $55.6(16.3)$ & $46.1(16.7)$ & $56.0(16.7)$ \\
\hline Not followed & $45.3(18.0)$ & $55.3(18.5)$ & $43.5(17.2)$ & $54.2(18.3)$ & $41.7(17.3)$ & $54.7(18.1)$ & $43.6(17.4)$ & $54.6(18.3)$ \\
\hline \multicolumn{9}{|l|}{$\%(\mathrm{n})$ manual work ${ }^{\star}$} \\
\hline Followed at 18 months & $63.6(178)$ & $51.3(202)$ & $69.2(458)$ & $54.2(317)$ & $67.2(131)$ & $54.8(120)$ & $67.5(767)$ & $53.3(639)$ \\
\hline Not followed & $65.8(131)$ & $47.7(74)$ & $71.7(269)$ & $62.4(148)$ & $63.1(82)$ & $46.0(40)$ & $68.5(482)$ & $54.7(262)$ \\
\hline \multicolumn{9}{|c|}{ Mean (SD) daily cigarette consumption $†$} \\
\hline Followed at 18 months & $15.6(9.2)$ & $17.0(13.6)$ & $15.8(8.7)$ & $18.0(13.7)$ & $16.6(9.6)$ & $17.9(13.6)$ & $15.9(9.0)$ & $17.7(13.7)$ \\
\hline Not followed & $15.1(10.3)$ & $16.3(14.5)$ & $16.5(9.4)$ & $17.6(14.4)$ & $15.2(9.5)$ & $18.7(14.7)$ & $16.0(9.7)$ & $17.4(14.5)$ \\
\hline \multicolumn{9}{|c|}{$\%$ (n) ex-smokers for $<1$ year } \\
\hline Followed at 18 months & _- & $10.7(43)$ & - & $12.7(76)$ & - & $10.4(23)$ & - & $11.6(142)$ \\
\hline Not followed & - & $13.4(50)$ & - & $16.3(107)$ & - & $18.3(40)$ & - & $15.8(107)$ \\
\hline
\end{tabular}

* Type of work only available for those followed at 6 months.

†Former smoking for ex-smokers.

Number not recorded for followed smokers: type of work (22)

Number not recorded for smokers not followed: sex (1), age (45), type of work (92).

Number not recorded for followed ex-smokers: type of work (24).

Number not recorded for ex-smokers not followed: age (19), type of work (36).

intervention groups corresponded to different populations. Therefore, any differences in the populations' natural propensity to stop smoking or remain abstinent would be spuriously attributed to the intervention unless adjusted for in the analysis. Additionally, even though we protected against it by not telling subjects or interviewers that they were in a smoking study, if more subjects with a higher propensity to change smoking behaviour were followed in some regions than others, this might also have caused biases in the comparison of interventions. To counter these potentially confounding effects and compare the interventions on a like-for-like basis, comparisons of outcomes in the three conditions were adjusted for all demographic and pre-intervention smoking characteristics predictive of change. These were separately identified for smokers and ex-smokers and the predictive models then used to adjust intervention comparisons using multiple logistic regression.

For current smokers, 30 demographic and smoking history characteristics were considered in relation to the probability of stopping smoking, of which three had main effects and two were involved in interactions. Older smokers $(p=0.03)$, those smoking fewer cigarettes per day $(p<0.01)$, and those who wished to reduce the amount they smoked $(\mathrm{p}<0.01)$ were more likely to have stopped by follow up. Sex and manual/non-manual work had an interactive effect on stopping, such that only in men was non-manual work predictive $(\mathrm{p}<0.01)$. Characteristics which had no additional effect on stopping included: having cut down the number smoked; wanting to stop altogether; currently trying to stop; ever having stopped for more than 24 hours; ever having stopped for a week; worrying about the health effects of smoking; having a partner who smokes; age of starting smoking; type of cigarette smoked; having switched to a "low tar" brand; number of previous quit attempts; longest period of previous abstinence; perceived dependence on cigarettes; ethnicity; intention to give up in the future; perceived likelihood of being successful in next quit attempt; and length of time since previous quit attempt.

For ex-smokers, there was an association between the length of time since quitting and the probability of remaining abstinent, such that those who had stopped more recently were more likely to have relapsed $(p<0.001)$. Twenty three per cent of those who had stopped within the last year relapsed, while only $2 \%$ of those who had stopped for more than a year relapsed. Those who smoked more heavily before stopping $(p=0.01)$ and those who were persuaded to stop by someone else $(p<0.01)$ were also more likely to relapse. Other baseline characteristics, including all demographics, worrying about the health effects of smoking, and having a partner who smokes, did not predict who would remain off cigarettes.

There was no evidence that any predictors were related to outcome through quadratic or higher order terms for either smokers or ex-smokers, and no evidence that their relation to outcome differed between the intervention conditions.

INTERVENTION EFFECTS AFTER PHASE I OF THE CAMPAIGN

The effect of single (Granada) versus double (Tyne Tees, Yorkshire) weight advertisements shown during the first phase was tested. There was no evidence of an effect of intensity of advertisements as measured by responses at the six month follow up in smokers or ex-smokers. Among smokers, 6.6\% (48/728) and $6.3 \%(21 / 336)$ in the double and single weight conditions, respectively, reported stopping smoking (adjusted odds ratio 1.02, $\mathrm{p}=0.94)$. In ex-smokers, 96.4\% (537/557) and $97.0 \%(288 / 297)$ in double and single weight conditions, respectively, reported remaining abstinent (adjusted odds ratio 0.56, $p=0.15)$. There was also no evidence of any effects of the main interventions after the first phase of the campaign. Among smokers followed at six months, $7.4 \%$ (35/475), $6.5 \%$ $(69 / 1064)$, and $8.4 \%(28 / 334)$ in the Control, 
Table 3 Smoking cessation in those followed at 18 months

\begin{tabular}{|c|c|c|c|c|c|}
\hline & \multicolumn{3}{|c|}{ Unadjusted outcomes } & \multicolumn{2}{|c|}{ Adjusted odds ratio ( $95 \%$ CI) } \\
\hline & Control & TV media only & $T V$ media $+L T C N$ & $\begin{array}{l}\text { TV media only versus } \\
\text { control }\end{array}$ & $\begin{array}{l}T V \text { media }+L T C N \text { versus } T V \\
\text { media only }\end{array}$ \\
\hline $\begin{array}{l}\% \text { smokers giving up } \\
\text { cigarettes }\end{array}$ & $8.7(25 / 288)$ & $9.7(65 / 673)$ & $12.1(24 / 198)$ & $\begin{array}{l}1.27(0.77 \text { to } 2.08)^{\star} \\
p=0.35\end{array}$ & $\begin{array}{l}1.27(0.763 \text { to } 2.11)^{\star} \\
p=0.35\end{array}$ \\
\hline $\begin{array}{l}\% \text { ex-smokers } \\
\text { remaining off cigarettes }\end{array}$ & $94.5(380 / 402)$ & $96.3(576 / 598)$ & $96.4(214 / 222)$ & $\begin{array}{l}2.21(1.11 \text { to } 4.40) \dagger \\
\mathrm{p}=0.025\end{array}$ & $\begin{array}{l}0.840(0.345 \text { to } 2.04) \\
p=0.70\end{array}$ \\
\hline $\begin{array}{l}\text { Pooled common effect } \\
\text { on not smoking }\end{array}$ & - & - & - & $\begin{array}{l}1.53(1.02 \text { to } 2.29) \\
\mathrm{p}=0.04\end{array}$ & $\begin{array}{l}1.15(0.737 \text { to } 1.78) \\
\mathrm{p}=0.55\end{array}$ \\
\hline
\end{tabular}

^Adjusted for predictors of giving up cigarettes: sex, age, manual/non-manual, daily cigarette consumption, "want to reduce smoking", and sex by manual/non-manual interaction.

†Adjusted for predictors of remaining off cigarettes: number of cigarettes smoked per day before stopping, length of time since stopping, whether persuaded to stop smoking by somebody else.

TV media, and TV media plus LTCN conditions, respectively, reported having stopped. After adjustment for background characteristics, the odds ratio for smoking cessation for TV media versus Control was 0.97 ( $p=0.89$ ), and for TV media plus LTCN versus TV media, $1.19 \quad(\mathrm{p}=0.52)$. Among ex-smokers, 96.5\% (551/571), 96.6\% (825/ 854), and $97.1 \%(303 / 312)$ in Control, TV media only, and TV media plus LTCN conditions, respectively, reported remaining abstinent. After adjustment for background characteristics, the odds ratio for remaining abstinent for TV media versus control was 1.18 ( $p=0.59)$, and for TV media plus LTCN versus TV media only, $1.28(\mathrm{p}=0.56)$.

INTERVENTION EFFECTS AFTER PHASE I AND II By 18 months, 9.8\% (114/1159) of successfully followed smokers reported having stopped, and $95.7 \%(1170 / 1222)$ of exsmokers reported remaining abstinent - that is, $4.3 \%$ relapsed. Although the observed effect of TV media compared to controls was higher in ex-smokers than in smokers, there was little evidence that these effects differed $\left(\chi^{2}=2.5\right.$, $\mathrm{p}=0.2$ ), and the adjusted odds ratios were pooled to estimate common intervention effects on not smoking (table 3). Likewise, there was no evidence of heterogeneity between smokers and ex-smokers in the effect of LTCN additional to TV media ( $1.3 v 0.8$, $\left.\chi^{2}=0.8, \mathrm{p}=0.4\right)$, and these adjusted odds ratios were also pooled.

TV media compared to no intervention was estimated to have increased the odds of not smoking by $53 \%$, although the confidence interval was wide. The adjusted odds ratio for the effect of TV media plus LTCN over control was $1.67(95 \%$ CI 1.0 to $2.8, p=0.049)$, but there was no evidence that LTCN had an effect additional to the TV campaign.

Since the initial smoking prevalence rates in the TV regions selected for this study were different, we chose not to estimate directly the impact of the TV campaign on smoking prevalence, but rather to measure the effect on smokers and ex-smokers independently of the population characteristics using the odds ratio. However, our odds ratio can be used to estimate the likely impact on a population with a given prevalence because it was adjusted for predictive background characteristics which would also be evident in other populations. The effect of the campaign is most easily seen in a population where the prevalence of smok- ing is not changing, as is currently the situation in several developed countries, and where $5 \%$ of smokers would stop and 5\% of ex-smokers relapse over an 18 month period without the TV advertising campaign. The introduction of the TV campaign would increase the odds of quitting and the odds of remaining abstinent by a factor of 1.53 , giving a quit rate among smokers of $7.45 \%$ and a relapse rate among ex-smokers of $3.33 \%$. Assuming a preintervention smoking prevalence rate of $28 \%$ and an ex-smoker rate of $28 \%$, the campaign would reduce smoking prevalence by an estimated $1.2 \%$, to $26.8 \%$. In a population where $30 \%$ smoke and $26 \%$ are ex-smokers, the effect of the campaign would be larger, producing a reduction of $1.4 \%$ in prevalence to $28.6 \%$. Conversely, were there fewer smokers $(26 \%)$ than ex-smokers $(30 \%)$, the effect would be smaller with a $0.94 \%$ reduction in prevalence.

\section{Discussion}

The HEA's anti-smoking TV campaign was effective in promoting a reduction in smoking prevalence, but this only became evident after both phases of the campaign had been completed over an 18 month period. Although the largest impact was observed when the TV campaign was screened in conjunction with local tobacco control activity, there was no evidence of an extra effect of the local activity. There was also no evidence of an effect of varying the weight of TV advertisements during the first phase of the campaign.

Although there is previous evidence that media only interventions can affect individuals smoking behaviour, greater effects have often been observed when community activities accompany the campaign. ${ }^{5}$ The failure of the LTCN to show an additional impact when operating alongside our TV media campaign was, therefore, disappointing, but should not necessarily be interpreted as meaning that the LTCN would not be effective when operating without this type of TV advertising support. Unfortunately, our design did not allow for a separate estimation of the effect of the LTCN without TV advertising. However, unless there was an interaction between the effects of the TV campaign and the LTCN, such that the effect of LTCN was masked by the presence of the TV campaign, then our results suggest that the effect of adding LTCN to the TV campaign was smaller than that of the TV campaign itself 
and too small to be detected by a study of this size. If so, the most likely explanation is that more time was needed before the start of the study to allow the network to become optimally effective.

Also disappointing was the failure of this study to detect an immediate impact of the TV advertising after the first phase screenings. Given that the TV campaign had a clear effect over 18 months, it is likely that there was some positive effect over the short term, but that this was too small to be detected in our study. Since double weight screening during this period did not show an effect over no advertising, then it is not surprising that it was not seen to be more effective than single weight advertising. The overall implication of these results is that for this type of advertisement a longer campaign period is required when advertising is purchased at this weight. In this study we were not able to assess the specific effect of dividing the TV campaign into two phases, with a period of some eight months between them, as compared to alternative scheduling strategies.

There are several possible sources of bias and confounding which might have affected our results and which need consideration. First, our outcome measure was self reported smoking status and we did not include validation of smoking status with a biochemical marker of smoke intake. This may have led to a small number of smokers being incorrectly classified as having stopped, but, if so, these are likely to have been equally distributed across the intervention conditions since respondents were unaware that the interviews were associated with the interventions. ${ }^{26}$ Also, we measured largely short term cessation with about $50 \%$ of those who stopped during the campaign reporting having done so within the past six months. Many will have subsequently returned to smoking and the effect of the intervention on lifetime cessation, leading to a measurable reduction in health risk, will have been less. ${ }^{22}$

Given the nature of the delivery of mass media interventions it was not possible to include individual randomisation to interventions in this study, and the possibility that the results were biased by unequally distributed antecedent factors affecting outcome cannot be entirely discounted. We adjusted the comparisons for all predictors of outcome recorded at baseline, but if there were others which were unequally distributed in the intervention populations, then a bias in our results might remain. This is unlikely, however, since we considered most characteristics (or correlates of them) known to be predictive of outcome in this population. ${ }^{27-29}$

Claims of the campaign's effectiveness have to be made in relation to the wide range of concurrent anti-smoking activity. The No Smoking Day campaign was running at the same time as our intervention, as were a number of advertisements for nicotine replacement therapy. The total media spend in the UK during the HEA campaign period for a total of 10 different products marketed to help smokers stop amounted to $£ 12.4$ million. Also, during the campaign period the cost of a packet of cigarettes rose by $6.5 \%$ as a result of increased taxation, which may have had a positive effect on cessation. Against this anti-smoking activity, it is estimated that the tobacco industry were promoting smoking by spending more than $£ 100$ million per year on advertising and sponsorship in England. ${ }^{30}$ However, as all these campaigns and fiscal measures were national initiatives with no regional bias it can be assumed that the same level of extraneous anti-smoking or prosmoking "noise" existed in all intervention regions.

This study evaluated only one particular type of presentation of anti-smoking TV advertisement, which it might not be possible to repeat with the same effect, but demonstrates the considerable potential of such interventions. Although different in nature from the BBC TV series "So you want to stop smoking", screened in the 1980s, our campaign had broadly similar results, which suggests that a wide range of TV publicity styles can be effective. ${ }^{631}$ The net effect of reducing adult smoking prevalence by about $1.2 \%$ would have a major impact on reducing smoking related diseases, were similar campaigns to be repeated on a regular basis. Such campaigns are also likely to prove highly cost effective compared to other health interventions. Unless the population prevalence of smoking is reduced it is unlikely that the UK government's recent public health targets for reducing cancer and heart disease deaths over the next 10 years will be met. ${ }^{32}$

This study was funded by the Health Education Authority for England. We thank Helen Ryan, Lesley Owen, Ann McNeill, Donald Reid, and Charles Gallichan of the Health Education Authority for England for their assistance with the design and Authority for England for their assistance with the design and
implementation of this study. Thanks are also due to Patricia implementation of this study. Thanks are also due to Patricia
Hodgson and the West Yorkshire Smoking and Health Network Hodgson and the West Yorkshire Smoking and Health Network
for their work in building the local smoking alliance and to for their work in building the local smoking alliance and to
Abbot, Mead and Vickers who managed the advertising elements of the campaign.

1 Peto R, Lopez AD, Boreham J, Thun M, Heath Jr C, Doll R. Mortality from smoking worldwide. Br Med Bull 1996; 52:12-21.

2 The Department of Health. Smoking kills: a white paper on tobacco. London: HMSO, 1998.

3 Silagy C, Mant D, Fowler G, Lancaster T. Nicotine replacement therapy for smoking cessation (Cochrane Review). In: The Cochrane Library, Issue 1, 1999. Oxford: Update In: The Coci

4 Raw M, McNeill A, West R. Smoking cessation guidelines for health professionals: a guide to effective smoking cessation interventions for the health care system. Thorax 1998;53(suppl 5, pt1):1-19.

5 Flay BR. Mass media and smoking cessation: a critical review. Am f Public Health 1987;77:153-60.

6 Sutton SR, Hallett R. Experimental evaluation of the BBC TV series "So you want to stop smoking." Addict Behav 1987;12:363-6.

7 Pierce JP, Gilpin EA, Emery SL, et al. Has the California tobacco control program reduced smoking? $f A M A$ tobacco control

8 Pierce JP, Gilpin EA, Emery SL, et al. Tobacco control in California: who's winning the war? An evaluation of the tobacco control program, 1989-1996. La Jolla, California: University of California, San Diego, 1998. http:// ssdc.ucsd.edu/tobacco/reports

$9 \mathrm{Hu}$ T, Sung H, Keeler TE. Reducing cigarette consumption in California: tobacco taxes vs. an anti-smoking media campaign. Am f Public Health 1995;85:1218-22.

10 Harris JE, Connolly GN, Brooks D, Davis B. Cigarette smoking before and after an excise tax increase and an anti-smoking campaign-Massachusetts, 1990-1996. anti-smoking campaign-Massachusetts, 1990-18

11 Anon. Independent evaluation of the Massachusetts tobacco control program: fifth annual report. http://www.state.ma.us/ $\mathrm{dph} / \mathrm{mtcp} /$ home.htm 
12 Pizacani B, Mosbeck C, Hedberg K, et al. Decline in cigarette consumption following implementation of a gram - Oregon, 1996-1998 MMWR Morbid Mortal Wkly Rram - Oregon, 1996-1.

13 Anon. Executive summary: Oregon's tobacco prevention and education program. http://www.ohd.hr.state.or.us/cdpe/ hpcdp/tobacco/welcome.htm

14 Pierce JP, Dwyer T, Frape G, Chapman S, Chamberlain A, Burke N. Evaluation of the Sydney "Quit for Life" anti-smoking campaign. Part 1. Achievement of intermediate goals. Med F Aust 1986;144:341-4.

15 Dwyer T, Pierce JP, Hannam CD, Burke N. Evaluation of the Sydney "Quit for Life" anti-smoking campaign. Part 2. Changes in smoking prevalence. Med F Aust 1986;144:344-7.

16 Pierce JP, Macaskill P, Hill D. Long-term effectiveness of mass media led anti-smoking campaigns in Australia. $A m \mathcal{F}$ Public Health 1990;80:565-9.

17 Anon. Australia's national tobacco campaign: evaluation report. http://www.health.gov.au/pubhlth/publicat/document/ metadata/tobccamp.htm

18 Egger G, Fitzgerald W, Frape G, et al. Results of large scale media anti-smoking campaign in Australia: North Coast "Quit for Life" programme. BMF 1983;287:1125-8.

19 Anon. 1991 census: definitions. OPCS, England and the General Register Office, Scotland. London: HMSO, 1992

20 Kish L. Survey sampling. New York: John Wiley, 1965.

21 Office of National Statistics. Living in Britain: results from the 1994 general household survey. London: HMSO, 1996.

22 Stapleton JA, Sutherland G, Russell MAH. How much does relapse after one year erode effectiveness of smoking cessation treatments? Long term follow up of randomized trial of nicotine nasal spray. BMF 1998;316:830-1.
23 Office of National Statistics. Living in Britain: results from the 1996 general household survey. London: HMSO, 1998

24 Foulds J, Stapleton JA, Hayward M, et al. Transdermal nicotine patches with low-intensity support to aid smoking cessation in outpatients in a general hospital. Arch Fam Med 1993;2:417-23.

25 Fleiss JL. The statistical basis of meta-analysis. Statistical Methods in Medical Research 1993;2:121-45.

26 Glasgow RE, Mullooly JP, Vogt TM, et al. Biochemical validation of smoking status: pros, cons, and data from four low-intensity intervention trial. Addict Behav 1993; 18:511-27.

27 Jackson PH, Stapleton JA, Russell MAH, Merriman RJ. Predictors of outcome in a general practitioner intervention against smoking. Prev Med 1986;15:244-53.

28 Jarvis MJ. Patterns and predictors of smoking cessation in the general population. In: Bolliger CT, Fagerstrom KO, eds. The tobacco epidemic. Basel: Karger, 1997.

29 Stapleton JA, Russell MAH, Feyerabend C, Wiseman SM, Gustavsson G, Säwe U. Dose effects and predictors of outcome in a randomized trial of transdermal nicotine in general practice. Addiction 1995;90:31-42.

30 Action on Smoking and Health. Tobacco promotion. In: The fact file. London: ASH, 1997.

31 Flay B. Selling the smokeless society: 56 evaluated mass media programs and campaigns worldwide. American public health practice series, 1987. Washington DC: American Public Health Association.

32 Department of Health. Saving lives: our healthier nation. A White Paper. London: HMSO, 1999. 